\title{
Social Support and Self-care in Heart Failure
}

\author{
Robyn Gallagher, Marie-Louise Luttik and Tiny Jaarsma
}

\section{Linköping University Post Print}

N.B.: When citing this work, cite the original article.

Original Publication:

Robyn Gallagher, Marie-Louise Luttik and Tiny Jaarsma, Social Support and Self-care in Heart Failure, 2011, Journal of Cardiovascular Nursing, (26), 6, 439-445.

http://dx.doi.org/10.1097/JCN.0b013e31820984e1

Copyright: Lippincott, Williams \& Wilkins http://www.lww.com/

Postprint available at: Linköping University Electronic Press

http://urn.kb.se/resolve?urn=urn:nbn:se:liu:diva-71508 
Social support and self-care in heart failure.

Gallagher R, Luttik ML, Jaarsma T. 


\begin{abstract}
:
Background and Objective: Self-care by heart failure (HF) patients is essential for optimal disease management of their condition. However, as the nature of HF is unrelenting and burdensome self-care is usually achieved with the support of partners. It is not clear what role the level of social support by partners plays in HF self-care, therefore this study sets out to determine the types of social support provided to HF patients and the impact of differing levels of social support on HF patients' self-care
\end{abstract} Subjects and Method: A secondary analysis of a subgroup of patients experiencing their second hospital admission for $\mathrm{HF}$ at baseline in the $\mathrm{COACH}$ study, a multi-site trial conducted in the Netherlands. Measures included the European Heart Failure Self-care Behaviour Scale and a multiple component assessment of social support, which categorised patients into low, moderate and high levels of social support according to the presence of a partner and their perception of support they received from their partner. Results and Conclusions: Patients $(n=333)$ had an average age of 72 years (SD 11) and 92\% had a New York Heart Association of III or more. Of the patients with partners $(56 \%)$, only $49 \%$ had a high level of support from their partner. No demographic or clinical characteristic was associated with self-care behaviour. Patients with a high level of support reported significantly better self-care $(\mathrm{p}=.002)$ than patients with low or moderate levels of social support. Patients with a high level of social support reported being significantly more likely to consult with a health professional for weight gain $(\mathrm{p}=$ $.011)$, to limit the amount of fluids they have $(\mathrm{p}=.02)$, take their medication $(\mathrm{p}=.017)$, 
to get a flu shot $(\mathrm{P}=.001)$ and to exercise on a regular basis $(\mathrm{p}<.001)$ than those with medium or low levels of social support.

The presence of social support by a partner is not sufficient to influence HF patients' selfcare. Social support provided by partners needs to be of a quality and content that matches HF patients' perception of need to influence self-care. Caregivers, especially partners, should be considered as integral in the treatment and care of HF patients.

Keywords: Heart failure, self-care, social support, partners

\section{Summary of what this paper adds:}

Social support provided to HF patients may be categorised according to patients' perceptions of their partners' support.

Social support provided by partners of a quality and content that matches HF patients' needs is associated with better self-care, particularly in the key areas of taking medications, managing fluid intake, consulting health professionals for weight gain, having a flu shot and regular exercise.

When assessing HF patients' capacity for self-care, the partners and the partners' relationship with the patient should also be assessed. 


\section{Summary of what this paper adds:}

Social support provided to HF patients may be categorised according to patients' perceptions or knowledge of that support.

Social support provided by partners of a quality and content that matches HF patients'

needs is associated with better self-care, particularly in the key areas of taking

medications, consulting health professionals for weight gain, having a flu shot and

regular exercise.

When assessing HF patients' capacity for self-care, the partners and the relationship with the patient should also be assessed. 


\section{Introduction}

Recent heart failure (HF) guidelines emphasise the fundamental role that HF patients have in managing their condition using good self-care. ${ }^{1}$ Routinely practiced self-care by HF patients can reduce hospital admission ${ }^{2}$ and mortality, ${ }^{3}$ potentially limiting the impact of HF on quality of life. However, the care required for HF is complex, unrelenting and increasingly burdensome, as the HF worsens and comorbid conditions appear. It is not surprising then that many patients experience difficulty with HF self-care and often need the support of others such as spouses, who consequently also make an important contribution to HF patients' care. ${ }^{4,5}$

It is commonly believed that social support influences HF patients' outcomes through better self-care. However, while there is substantial evidence for this link in people with other chronic diseases such as diabetes, the evidence for the effect of social support on self-care in HF patients is ambiguous. ${ }^{6,7}$ While some studies describe in detail the way that family and friends can support self-care ${ }^{8.9}$ and the development of self-care skills in HF patients, ${ }^{10}$ most quantitative studies report no independent effect of social support on HF self-care. For instance, a multinational study of $2082 \mathrm{HF}$ patients at varying levels of severity of HF found that marital status had no effect on patients' self-care as measured by the Self-care of Heart Failure Index. ${ }^{11}$ Similarly, several recent studies have reported no independent effect of social support on HF self-care, regardless of the way social support was measured; for instance, as perceived emotional support ${ }^{12}$ or marital status. ${ }^{13,14}$ Ultimately, only one published study was found that linked social support and HF patients' self-care, in this case indicating that lack of social support, as measured by 
not having a partner, was associated with worse self-care overall. ${ }^{15}$ Together these results suggest that there is a need to differentiate the effect of having a partner from the level of support the partner provides.

In contrast to overall HF self-care, there is more evidence that social support effects individual self-care behaviours and these effects are not consistently positive. For instance, social support has been found to have an independent positive effect on medication adherence ${ }^{8,16}$ and dietary self-care/adherence. ${ }^{16}$ In contrast, married HF patients reported less self-care in terms of taking less rest when they were short of breath and less frequent monitoring of fluid intake than patients who were not married. ${ }^{17}$ This is an important reminder that the effects of social support may be complex, and the authors of this study suggest that the negative effects arose because married patients may feel more bound to the household routine for eating and activity, thereby limiting independent control over some areas of self-care. In fact, HF patients may regularly be required to give precedence to family events and responsibilities rather than to HF self-care. ${ }^{7}$ Therefore it is important to incorporate patients' perceptions of the quality and usefulness of the support they are provided by partners into HF self-care research.

While many definitions and theoretical views on social support exist, one of the most common definitions arises from a framework developed by House et al. ${ }^{18}$ In this framework social support refers to positive relationships that promote health and buffer stress. The nature of social support therefore incorporates multiple aspects including the quality of the relationship, caring and concern for the person, practical and emotional 
support and provision of information support. However, few studies have incorporated all of these aspects into the measure of social support or investigated whether social support does influence HF self-care. In particular, the multiple aspects of support that partners provide have not been well-investigated. For example, while the partners' knowledge of HF and attention to HF symptoms does not necessarily determine the level of support for HF self-care, ${ }^{19}$ lack of knowledge and attention may certainly limit the quality of the support provided. ${ }^{10}$ However, no study was found that included multiple aspects in the measure of social support by partners for HF patients or compared the presence of different levels of social support by partners to patients without partners. As a result, it is difficult to determine the role that social support plays in HF patients' self-care. We therefore developed a novel measure of social support to 1) determine the types and level of social support provided by partners to HF patients, and 2) the impact of differing levels of social support by partners versus patients without partners on HF patients' selfcare.

\section{Method}

\section{Study design and sample}

The study has a cross-sectional descriptive design and represents a secondary analysis of a subgroup of patients from the $\mathrm{COACH}$ study, a multi-site trial conducted in the Netherlands. ${ }^{20}$ As the detail of the parent study has been supplied previously, it is provided in summary form below. Patients were eligible for the study if they had been admitted to hospital for HF with a New York Heart Association (NYHA) functional classification of II-IV, with evidence of underlying structural heart disease and if they were aged at least 18 years. Patients were excluded if they had undergone cardiac surgery 
or a percutaneous coronary intervention in the previous six months or if these procedures or heart transplantation were planned. Further reasons for exclusion included being unable to participate in the $\mathrm{COACH}$ intervention or to complete the data collection forms. The human research ethics committee of participating sites approved the study and all participants provided informed consent.

For the present substudy we selected patients who had been admitted to the hospital for HF at least once before the initial hospitalization when patients were included into the $\mathrm{COACH}$ study. These patients therefore were familiar with the requirements for HF selfcare. Only baseline data, collected before randomization of the study were used for this analysis and therefore assignment of groups was not used in the analysis.

\section{Measures}

Clinical data on NYHA functional class, comorbid illnesses and hospital admissions for HF were collected from the medical record and sociodemographic data, which included age, gender, marital status and living arrangements, were collected from the patient. In addition, patients were asked to rate their partners' health on a five point scale from excellent to poor, and to indicate whether their partner had problems in daily activity due to impaired physical health or emotional problems using a yes/no response.

HF self-care behaviour: The European Heart Failure Self-care Behaviour Scale ${ }^{21}$ was used to collect data on self-care behaviour specifically related to HF. For each of 12 selfcare behaviours patients indicate their response on a five-point scale between 1 (I 
completely agree) and 5 (I completely disagree). Individual item responses are then totalled for an overall self-care score from 12 to 60, with higher scores reflecting less participation in self-care behaviours. The validity and reliability of the EHFSCBS have been tested and confirmed in multiple samples. ${ }^{21,22}$ In this sample the internal consistency reliability was adequate at Cronbach's alpha of .71.

1. Social support was defined in this study to be the aspects of relationships with a partner which promote health or buffer stress including instrumental aid, emotional caring or concern and information (House et al ref). The measure was created from a survey using multiple items indicating three levels of social support for the HF patient. Support was provided by partners with whom patients were living and had an intimate relationship. While there are many potential sources of social support for HF patients, in most cases social support is provided in an enduring way by these partners or spouses. Therefore, if the patient did not have a partner they were included in the category of low support for this study. However, when patients had a partner, the partner's provision of support was categorised into moderate and high perceived levels of support using assessment of multiple dimensions including: The level of informational support was measured using the patient's perception of the adequacy of their partner's HF knowledge assessed by a single item with yes/no responses.

2. The level of instrumental and emotional support was measured from the patient's perception in three respects; the level of perceived practical, and emotional support and attention to the patient's HF symptoms. A single item was 
used each of these areas, however, responses to the items on the amount of practical and emotional support the partner provided were indicated on a scale from no support to very much support with higher scores reflecting more support. Whereas whether the partner paid attention to the patient's HF symptoms was indicated by a yes/no response.

3. The quality of the relationship was measured from the patient's perception of their relationship with their partner using a single item with responses indicated on a scale from 0-10, with higher scores reflecting a better quality relationship.

To create the categories of partner support all scores were dichotomised and two points allocated to the better score as follows: a yes response from patients on the partner having adequate HF knowledge, a very much or much response by patients to whether the partner provides emotional or practical support, a yes response by patients to whether the partner pays attention to their HF symptoms and a score of 8 or more by patients for the quality of the relationship with their partner. The points were then summed to achieve a potential score of 10 , and patients were then categorised into moderate and high levels of support using the median score of 9 . This meant patients scoring more than 9 points were categorised as having a high level of support from their partners and scores of less than or equal to 9 were categorised as having a moderate level of support from their partners. The social support measure had high internal consistency reliability at Cronbach's alpha of .96 , indicating potential redundancy of items.

\section{Procedure}


Patients were recruited into the study following provision of informed consent. All data were collected at hospital discharge. Data on clinical and socio-demographical characteristics of the patients was collected from medical records and interviews at admission to the hospital.

\section{Data Analysis}

Data were analysed using SPSS version 17. Means, medians, frequencies and percentages have been used to describe the data according to the level and the distribution of the data. For normally distributed interval data such as self-care, the relative influence of sociodemographic and clinical variables were determined using t-tests and one-way ANOVA. However, some of the individual self-care behaviours scores were not normally distributed so Kruskall-Wallis was used, followed by chi-squared to determine the effects of level of social support as recommended by Field. ${ }^{23}$ The p-level has been set at .03 to allow for multiple comparisons. ${ }^{23}$ Multiple regression analysis was used to determine the independent predictors of self care behaviour using the variables age, gender, education, comorbidity, depression, NYHA class, previous admissions and category of support, with all variables entered at once as recommended for exploratory analyses. ${ }^{23}$

\section{Results}

\section{Demographics:}

Patients $(\mathrm{n}=333)$ in the sample had an average age of 72 years (SD 11), were mostly male $(66 \%)$ and approximately half the sample (56\%) had a partner (Table 1). Comorbidities were common, particularly diabetes (36\%), COPD (34\%) and depressive 
symptoms (39\%). The majority of the patients had moderate severity HF as classified by having a NYHA class of III or more (92\%). The current admission was the second HF related admission for a little more than half the patients (58\%), while the other patients had more than two such admissions.

All patients identified an opposite sex partner. Patients' partners had a mean age of 67 years (SD 11) and were mostly female with good or better health (42\%), although physical (32\%) and emotional (22\%) problems were relatively common (Table 1).

\section{Partners' provision of support}

The partners were perceived by the HF patients to support them in multiple ways (Table 2). The majority of patients rated their partners' support at a high level for practical support (82\%), emotional support (87\%) and attention to HF symptoms (95\%). However, a high rating occurred less often (49\%) for the quality of the relationship with their partner. Furthermore, only a little more than half of the patients $(58 \%)$ described their partners as having adequate knowledge of HF. There was no difference for support characteristics by gender of the patient, except for the substantial difference in the proportion of male patients $(97 \%)$ who described their partner as paying attention to their symptoms versus female patients $(14 \%)(\mathrm{p}=.009)($ Table 3$)$. Using the techniques described in the method, $49 \%$ of the patients with partners were categorised as having a high level of support from their partner (Table 4). There was no difference in the level of support by patient gender. 


\section{Provision of support and self-care}

Patients' self-care was at a moderate level, with the average score 25.59 (SD 6.16) out of a potential 60 points. Age, gender, education level, comorbidities (including depression) and NYHA were not associated with self-care behaviour (Table 5.) The level of social support was related to the level of self-care, so that patients with a high level of support reported significantly better self-care $(\mathrm{p}=.003)$. Multiple regression analyses was used to determine the independent predictors of HF self care behaviour, however the model did not fit the data well $\left(\mathrm{F}=1.98, \mathrm{p}=.06, \mathrm{R}=.22, \mathrm{r}^{2}=.05\right)$, and the only significant predictor was a high level of support (versus low level) $(\beta=-2.65,95 \%$ confidence interval - $4.45--.85)$ as lower self-care scores reflect better self-care.

The self-care behaviours that patients reported performing most often were taking it easy when short of breath, taking a rest during the day, taking medications as prescribed and getting a flu injection every year; whereas daily weighing and regular exercise were least common. There were significant differences in the reporting of separate self-care behaviours according to the level of social support level (Table 6). Compared to those with low levels of support, patients with a high level of social support reported being significantly more likely to consult with a health professional for weight gain $(p=.02)$, to limit their amount of fluids $(p=.02)$, to take their medication $(p=.04)$, to get a flu shot $(\mathrm{P}=.01)$ and to exercise on a regular basis $(\mathrm{p}=.01)$. No differences were found between patients with a medium or low level of social support on any self-care behaviour.

\section{Discussion}


In this sample of HF patients who were currently hospitalized and had at least one previous HF related hospitalization, HF self-care was found to be at a moderate level only. Importantly, patients who had a high level of social support reported better overall self-care when social support was defined using multiple components to differentiate the levels of social support. In contrast, there was no difference between patients without partners and patients with partners who provided only moderate levels of support. Important deficits in perceived support occurred for partners' knowledge of HF and the quality of their relationship.

The level of perceived social support was significantly related to patients' overall HF self-care, but particularly to the specific self-care behaviours of contacting a health professional for weight gain, limiting the amount of fluids, taking medications, getting a flu shot and exercising regularly. All of these behaviours are important components of self-care for HF patients, particularly adhering to medications, which is a key behaviour in disease management and preventing hospital admission. ${ }^{24}$ Importantly, these results indicate that having a partner is not automatically associated with a positive outcome in self-care. Apparently partner support has most effect on patients' self-care when it reaches a certain level. Partners who provide a high level of support may be actively promoting HF patients' self-care. Previously, social support provided by partners has been conceptualized to promote patients' confidence or self-efficacy for HF self-care ${ }^{25,26}$ and there is also some evidence to suggest that partners help HF patients build the skills required for self-care ${ }^{10}$ However, it is likely that the partner's contribution to HF 
patients' self-care may involve some more direct processes as the partner's confidence is also related to the patient's survival. ${ }^{27-29}$

Heart failure makes stringent and complex demands on patients and their families, and in evaluating the level of social support to HF patients, the quality of the support needs to be taken into account. ${ }^{28}$ In our sample of HF patients who had some experience in self-care, a positive relationship between social support and self-care only occurred when social support was at a high level. This means that most benefits for self-care by HF patients happen not only when a partner is present, but when they have a good quality relationship with the partner and the partner provides them with appropriate support. The influence of the quality of the marital relationship on long-term survival especially in female patients has been described previously ${ }^{11}$ but the effect on self-care has not, and it is likely that the two are related and this is worth further investigation.

Traditional patient education might not be appropriate for supporting self-care skill development in patients with HF and their partners. ${ }^{19}$ As partners may be promoting the development of self-care skills and participating in decision-making it is crucial that patients and their partners are treated as collaborators. When assessing the HF patient's capacity for self-care the partner should also be assessed. Partners may have their own health problems, different knowledge level, expectations and underlying motivations related to the patient's HF self-care requirements. ${ }^{30}$ Attention should be paid both to individual ways of coping in patients and partners as well as to the way patients and partners collaborate and support each other. Given that female partners of male patients 
were much more likely to pay attention to their HF symptoms, there may be a need to support male partners' understanding and observation of HF symptoms.

\section{Limitations}

This study was a secondary analysis from a study that was not designed specifically to detect the role of social support. However, we feel that the results add to the existing data and can be seen as hypotheses generating. This study focused on the comparing between the levels of social support provided by partners and patients without partners. However, social support can arise from many sources other than and in addition to partners, therefore it is important that future studies explore the impact of these types of support. The measure and categories of social support have not been used previously either separately as contributors to social support or together as a composite measure and will require further development to determine the utility of both the complete scale and the individual components. Finally, it is likely that other important factors influence HF self care behavior as the multivariate model using the variables outlined in this study was not adequate.

\section{Conclusion and Implications}

The presence of social support is not sufficient to influence HF patients' self-care, instead social support provided by partners that is of a quality and content that matches patients' perceptions of need must be provided. Caregivers, especially partners, should be considered as integral in the treatment and care of HF patients. New teaching or counseling strategies are needed to optimize self-care in HF patients and their partners. 


\section{References}

1. Riegel B, Moser DK, Anker SD, Appel LJ, Dunbar SB, Grady KL et al. American Heart Association (AHA) Council on Cardiovascular Nursing; AHA Council on Clinical Cardiology; AHA Council on Nutrition, Physical Activity, and Metabolism; AHA Interdisciplinary Council on Quality of Care and Outcomes Research. State of the science: promoting self-care in persons with heart failure: a scientific statement from the American Heart Association. Circulation. 2009;120(12):1141-63.

2. Jovicic A, Holroyd-Leduc JM, Straus SE. Effects of self-management intervention on health outcomes of patients with heart failure: a systematic review of randomized controlled trials. BMC Cardiovasc Disord. 2006;6:43.

3. Ditewig JB, Blok H, Havers J, van Veenendaal H. Effectiveness of selfmanagement interventions on mortality, hospital readmissions, chronic heart failure hospitalization rate and quality of life in patients with chronic heart failure: A systematic review. Patient Educ Couns. 2010;78(3):297-315.

4. Luttik ML, Jaarsma T, Moser D, Sanderman R, van Veldhuisen DJ. The importance and impact of social support on outcomes in patients with heart failure: an overview of the literature. J Cardiovasc Nurs. 2005;20(3):162-9.

5. Clark AM, Reid ME, Morrison CE, Capewell S, Murdoch DL, McMurray JJ. The complex nature of informal care in home-based heart failure management. $J A d v$ Nurs. 2008;61(4):373-83.

6. MacMahon KM, Lip GY. Psychological factors in heart failure: a review of the literature. Arch Intern Med. 2002;162(5):509-16.

7. Gallant MP. The influence of social support on chronic illness self-management: a review and directions for research. Health Educ Behav. 2003;30(2):170-95.

8. Sayers SL, Riegel B, Pawlowski S, Coyne JC, Samaha FF. Social support and self-care of patients with heart failure. Ann Behav Med. 2008;35(1):70-9.

9. Dunbar SB, Clark PC, Quinn C, Gary RA, Kaslow NJ. Family influences on heart failure self-care and outcomes. J Cardiovasc Nurs. 2008;23(3):258-65. Erratum in: J Cardiovasc Nurs. 2008;23(4):370. 
10. Dickson VV, Riegel B. Are we teaching what patients need to know? Building skills in heart failure self-care. Heart Lung. 2009;38(3):253-61.

11. Lee CS, Riegel B, Driscoll A, Suwanno J, Moser DK, Lennie TA, Dickson VV, Cameron J, Worrall-Carter L. Gender differences in heart failure self-care: a multinational cross-sectional study. Int J Nurs Stud. 2009;46(11):1485-95.

12. Heo S, Moser DK, Lennie TA, Riegel B, Chung ML. Gender differences in and factors related to self-care behaviors: a cross-sectional, correlational study of patients with heart failure. Int J Nurs Stud. 2008;45(12):1807-15.

13. Kato N, Kinugawa K, Ito N, Yao A, Watanabe M, Imai Y, et al. Adherence to self-care behavior and factors related to this behavior among patients with heart failure in Japan. Heart Lung. 2009;38(5):398-409.

14. Cameron J, Worrall-Carter L, Riegel B, Lo SK, Stewart S. Testing a model of patient characteristics, psychologic status, and cognitive function as predictors of self-care in persons with chronic heart failure. Heart Lung. 2009;38(5):410-8.

15. Holzapfel N, Löwe B, Wild B, Schellberg D, Zugck C, Remppis A, et al. Selfcare and depression in patients with chronic heart failure. Heart Lung. 2009;38(5):392-7.

16. Wu JR, Moser DK, Chung ML, Lennie TA. Predictors of medication adherence using a multidimensional adherence model in patients with heart failure. $J$ Card Fail. 2008;14(7):603-14.

17. Artinian NT, Magnan M, Sloan M, Lange MP. Self-care behaviors among patients with heart failure. Heart Lung. 2002;31(3):161-72.

18. House JS, Umberson D, Landis KR Structures and processes of social support. Ann Rev Soc. 1988;14:293-318.

19. Clark AM, Freydberg CN, McAlister FA, Tsuyuki RT, Armstrong PW, Strain LA. Patient and informal caregivers' knowledge of heart failure: necessary but insufficient for effective self-care. Eur J Heart Fail. 2009;11(6):617-21.

20. Jaarsma T, Van Der Wal MH, Hogenhuis J, Lesman I, Luttik ML, Veeger NJ et al. Design and methodology of the COACH study: a multicenter randomised Coordinating study evaluating Outcomes of Advising and Counselling in Heart failure. Eur J Heart Fail. 2004;6(2):227-33. 
21. Jaarsma T, Arestedt KF, Mårtensson J, Dracup K, Strömberg A. The European Heart Failure Self-care Behaviour scale revised into a nine-item scale (EHFScB9): a reliable and valid international instrument. Eur J Heart Fail. 2009;11(1):99105.

22. Jaarsma T, Strömberg A, Mårtensson J, Dracup K .Development and testing of the European Heart Failure Self-Care Behaviour Scale. Eur J Heart Fail. 2003;5(3):363-70.

23. Field A. Discovering Statistics Using SPSS (Ed 2) 2009 London: Sage

24. Gislason GH, Rasmussen JN, Abildstrom SZ, MD, Schramm TK, Hansen ML, Buch P et al. Persistent use of evidence-based pharmacotherapy in heart failure is associated with improved outcomes. Circulation. 2007;116:737-744.

25. Reigel B Dickson V. A situation-specific theory of heart failure self-care. $J$ Cardiovasc Nurs. 2008;23(3):190-196.

26. Sebern M, Riegel B Contributionsn of supportive relationships to heart failure self-care. Eur J Cardiovasc Nurs. 2009;8(2):97-104.

27. Rohrbaugh MJ, Shoham V, Coyne JC. Effect of marital quality on eight-year survival of patients with heart failure. Am J Cardiol. 2006;98(8):1069-72.

28. Rohrbaugh MJ, Shoham V, Coyne JC, Cranford JA, Sonnega JS, Nicklas JM.Beyond the "self" in self-efficacy: Spouse confidence predicts patient survival following heart failure. J Fam Psychol. 2004;18(1):184-93.

29. Iqbal J, Francis L, Reid J, Murray S, Denvir M. Quality of life in patients with chronic heart failure and their carers: a 3-year follow-up study assessing hospitalization and mortality. Eur J Heart Fail. 2010 Jul 8 Epub ahead of print.

30. Annema C, Luttik ML, Jaarsma T. Reasons for readmission in heart failure: Perspectives of patients, caregivers, cardiologists, and heart failure nurses. Heart Lung. 2009;38(5):427-34 
Table 1. Patient and Partner Characteristics

\begin{tabular}{|c|c|c|}
\hline Patient Characteristic $(n=333)$ & Mean & (SD) \\
\hline \multirow[t]{2}{*}{ Age } & 72 & (11) \\
\hline & $\mathbf{N}$ & $(\%)$ \\
\hline Male & 218 & (66) \\
\hline \multicolumn{3}{|l|}{ Marital status } \\
\hline Married, living together & 185 & (56) \\
\hline Divorced & 12 & (4) \\
\hline Widowed & 95 & (29) \\
\hline \multicolumn{3}{|l|}{ Education } \\
\hline Primary & 120 & (36) \\
\hline Vocational education & 82 & (2) \\
\hline Secondary education & 88 & (27) \\
\hline Tertiary education & 32 & (10) \\
\hline \multicolumn{3}{|l|}{ Comorbidities } \\
\hline Diabetes Mellitus & 122 & (36) \\
\hline COPD & 112 & (34) \\
\hline Depressive symptoms (CESD >/= 16) & 129 & (39) \\
\hline \multicolumn{3}{|l|}{ Functional Classification NYHA } \\
\hline II & 21 & (6) \\
\hline III & 170 & (51) \\
\hline IV & 139 & (42) \\
\hline
\end{tabular}




\begin{tabular}{|l|ll|}
\hline Previous admission for HF & \multicolumn{2}{|c|}{} \\
One & 196 & $(58)$ \\
Two & 77 & $(34)$ \\
Three or more & 60 & $(80)$ \\
\hline Partner Characteristics (n = 186) Perceived by & Mean & (SD) \\
Patient & & \\
\hline Age & 66.81 & 11.1 \\
\hline & N & $(\%)$ \\
\hline Male & 43 & $(23)$ \\
\hline General health good or excellent & 79 & $(42)$ \\
\hline Problems in daily activities from physical health & 59 & $(32)$ \\
\hline Emotional problems & 41 & $(22)$ \\
\hline
\end{tabular}


Table 2. Partner Support for HF Patients $(n=186)$

\begin{tabular}{|l|l|}
\hline $\begin{array}{l}\text { Partner Support Characteristic } \\
\text { (support index score point }=2 \text { per characteristic) }\end{array}$ & N $\quad(\%)$ \\
\hline Patient believes partner has adequate HF knowledge & $106 \quad(58)$ \\
\hline Partner provides much/very much practical support & $152 \quad(82)$ \\
\hline Partner provides much/very much emotional support & $160 \quad(87)$ \\
\hline Partner pays attention to HF symptoms & $174 \quad$ (95) \\
\hline Quality of relationship with partner score $\geq 8(\mathrm{n}=149)$ & 73
\end{tabular}


Table 3. Support characteristics compared for patient gender in patients with partners

\begin{tabular}{|l|ll|ll|}
\hline \multirow{2}{*}{ Partner Support Characteristic } & \multicolumn{2}{|l|}{ Males } & \multicolumn{2}{l|}{ Females } \\
\cline { 2 - 6 } & $\mathrm{N}$ & $(\%)$ & $\mathrm{N}$ & $(\%)$ \\
\hline Patient believes partner has adequate HF knowledge & 85 & $(59)$ & 21 & $(52)$ \\
\hline Partner provides much/very much practical support & 117 & $(81)$ & 35 & $(85)$ \\
\hline Partner provides much/very much emotional support & 124 & $(86)$ & 36 & $(88)$ \\
\hline Partner pays attention to HF symptoms & 139 & $(97)$ & 6 & $(14) *$ \\
\hline Quality of relationship with partner score $\geq 8$ & 156 & $(48)$ & 17 & $(52)$ \\
\hline
\end{tabular}

$* \chi^{2}$ test $p=.009$ 
Table 4. Level of social support compared for gender of patients with partners

\begin{tabular}{|c|c|c|c|c|c|c|}
\hline \multirow[t]{2}{*}{ Group } & \multicolumn{2}{|c|}{$\begin{array}{l}\text { Low Support } \\
\text { (no partner) }\end{array}$} & \multicolumn{2}{|c|}{$\begin{array}{l}\text { Moderate } \\
\text { Support } \\
(</=9 \text { on } \\
\text { index })\end{array}$} & \multicolumn{2}{|c|}{$\begin{array}{l}\text { High Support } \\
(>9 \text { on } \\
\text { index })\end{array}$} \\
\hline & & $(\%)$ & & $(\%)$ & $\mathrm{N}$ & $(\%)$ \\
\hline Overall* & 138 & $(42)$ & & (28) & 94 & (29) \\
\hline $\begin{array}{l}\text { Males } \\
(n=144)\end{array}$ & & N/A & & (48) & 23 & $(59) \pm$ \\
\hline $\begin{array}{l}\text { Females } \\
(\mathrm{n}=42)\end{array}$ & & N/A & 75 & (52) & 19 & (45) \\
\hline
\end{tabular}


Table 5. Comparisons of patient characteristics and level of social support for patients' HF self-care

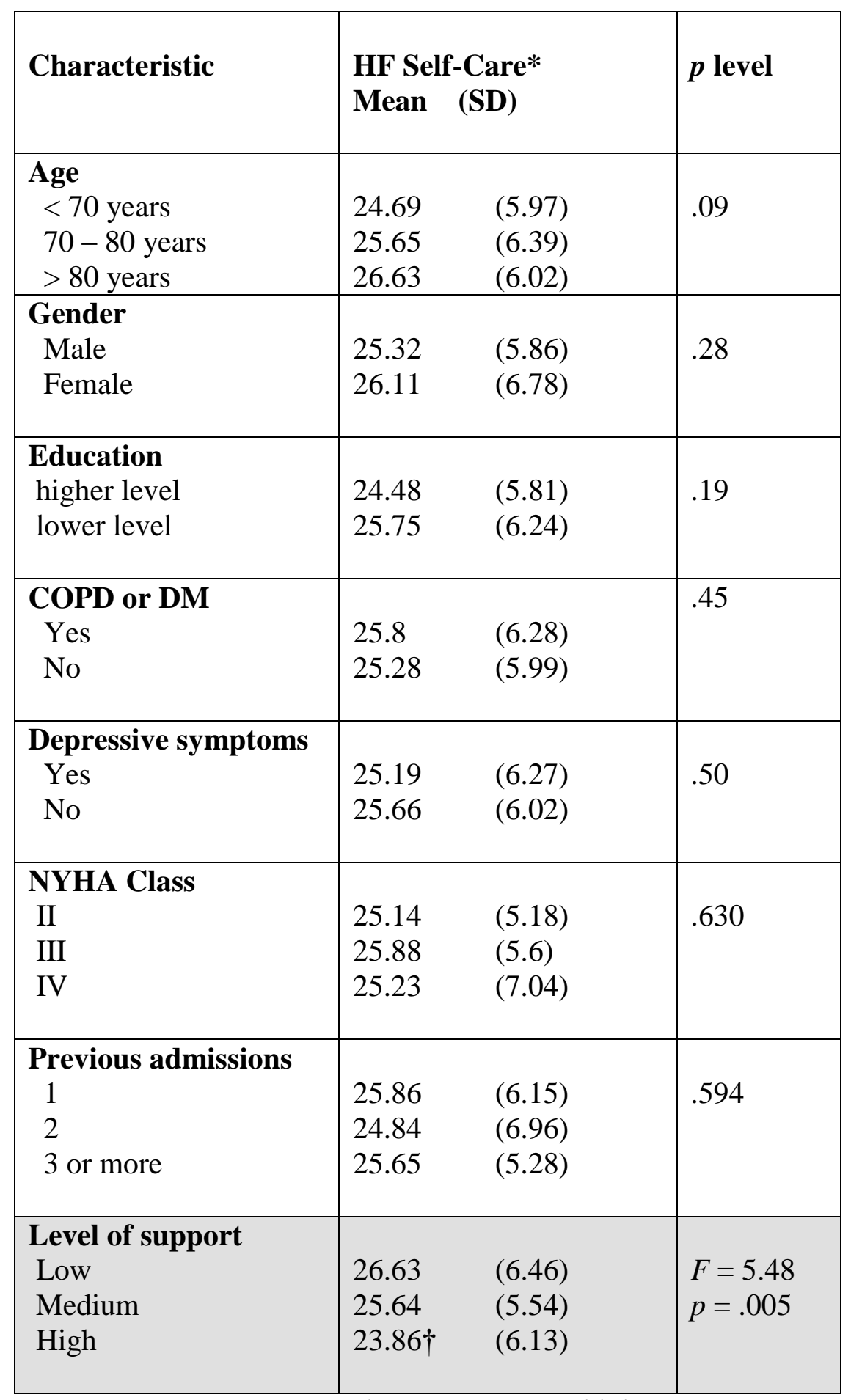

* higher scores are worse, $\uparrow$ Low support vs high support $\mathrm{p}=.003$, 
Table 6. Comparisons of specific HF self-care behaviours by level of social support

\begin{tabular}{|l|l|l|l|l|}
\hline $\begin{array}{l}\text { Self-care behaviours* } \\
\text { Mean (SD) }\end{array}$ & $\begin{array}{l}\text { Low } \\
\text { Support }\end{array}$ & $\begin{array}{l}\text { Medium } \\
\text { support }\end{array}$ & $\begin{array}{l}\text { High } \\
\text { support }\end{array}$ & P level \\
\hline I weigh myself every day & $3.46(1.4)$ & $3.1(1.41)$ & $3.2(1.46)$ & .13 \\
\hline If I get SOB I take it easy & $1.67(.78)$ & $1.69(.63)$ & $1.54(.63)$ & .19 \\
\hline $\begin{array}{l}\text { If SOB increases I contact my } \\
\text { doctor or nurse }\end{array}$ & $1.93(.97)$ & $2.02(1.0)$ & $2.0(1.08)$ & .85 \\
\hline $\begin{array}{l}\text { If leg/feet more swollen I } \\
\text { contact my doctor or nurse }\end{array}$ & $1.99(.91)$ & $2.01(1.02)$ & $1.87(.9)$ & .42 \\
\hline $\begin{array}{l}\text { If I gain weight I contact my } \\
\text { doctor or nurse }\end{array}$ & $2.45(1.19)$ & $2.09(1.01)$ & $2.08(1.1) \dagger$ & .022 \\
\hline $\begin{array}{l}\text { I limit the amount of fluids } \\
\text { I exercise regularly }\end{array}$ & $2.17(1.15)$ & $2.2(1.07)+$ & $1.84(.95) \dagger$ & .022 \\
\hline $\begin{array}{l}\text { I take a rest during the day } \\
\text { prescribed }\end{array}$ & $1.84(.97)$ & $1.85(.78)$ & $1.74(.89)$ & .36 \\
\hline $\begin{array}{l}\text { If I experience fatigue I } \\
\text { contact my doctor or nurse }\end{array}$ & $2.47(1.14)$ & $2.48(1.12)$ & $2.38(1.22)$ & .59 \\
\hline I eat a low salt diet & $2.11(1.16)$ & $2(1.01)$ & $2(1.02)$ & .85 \\
\hline $\begin{array}{l}\text { I take my medication as } \\
\text { I. }\end{array}$ & $1.64(.9)$ & $1.55(.7)$ & $1.34(.48) \dagger$ & .038 \\
\hline
\end{tabular}


* higher scores worse self-management, ANOVA/ Kruskal Wallis tests used, $\uparrow \mathrm{p}<.02$ high support Vs low support, $+\mathrm{p}<05$ moderate support Vs high support 